\title{
Curagen lays down markers, 120,000 of them
}

In mid-August, Curagen Corporation (New Haven, CT) announced it had identified more than 55,000 new single-nucleotide polymorphisms (SNPs) from its work in resequencing human expressed sequences. The company heralded the announcement as a "landmark discovery." Investors were pleased: the company's stock price rose around a third on the news. At the same time, the market's appreciation of Genset, another SNP company, continues to be subdued.

Following this most recent work, Curagen now has a database of over 120,000 SNPs from expressed regions (copy SNPs or cSNPs) of the human genome. Richard Shimkets, the company's director of internal discovery, says that this represents around $25 \%$ of the cSNPs that are most relevant to human medicine. He thinks that the cSNPs are already generating value for Curagen. "We believe that we can get intellectual property protection on the sequences per se. We have been aggressive in making patent filings on cSNPs."

Its technology portfolio has allowed Curagen to attract some big-name partners. In pharmacogenomics, it is working with Hoffmann-La Roche (Basel, Switzerland) and Glaxo Wellcome (GW; London, UK). Under the latter deal, worth US $\$ 2,750,000$ per year in research fees, Curagen will evaluate GW clinical candidate compounds in order to assess gene expression responses accociated with efficacy and toxicity. Revenues from other collaborations-with Pioneer Hi-Bred International (Des Moines, IA), Biogen (Cambridge, MA), and Genentech (S. San Francisco, CA)—are generating around $\$ 10$ million per year in fees.

Deborah Smeltzer, chief financial officer of Genset (Paris), a rival in the SNP wars, says that Genset is unimpressed with the Curagen announcement. "They have generated lots and lots of markers," she agrees, "But from what kinds of populations and at what frequency?" Genset is still in the process of building a map of SNP markers, the distribution of the alleles of which are roughly even. "We try to make sure that our SNPs occur at the right frequencies and can be applied universally across different populations," she explains. She expresses some doubts, too, about the validity of some of Curagen's markers. "You really have to qualify whether a single base difference in a DNA sequence is really a SNP or just a sequencing error," she points out.

Shimkets counters this by saying that Curagen only accepts a cSNP as such when it is found in at least two individuals or four separate chromosomes. How representative the cSNPs are is less clear because Curagen has not determined their frequency in the 300 people it has used to derive them. "We are not biasing things in terms of frequency," says Shimkets. He believes that Curagen's cSNP database is sufficient to satisfy its goal of candidate gene-based association studies. "Choose your 100-150 favorite genes in a disease. Then use the three or four variants that we have in each gene and use case-control or family studies to make the associations." Genset, in contrast, sees its major opportunity in association studies in diseases where multiple genes and multiple environmental factors may be involved. Genset has contrived to make its detection of associations between markers and SNPs significantly more sensitive by locating its SNPs onto a bacterial artificial chromosome physical map. Curagen will only have its set of markers comprehensively mapped when the human genome sequence nears completion. "The good news" says Shimkets "is that that is not too far off."

In this context, both the publicly funded completion of the sequencing project and the progress of the SNP consortium's publicly available SNP map (Nature Biotechnology, 17, 526) are ticking clocks for those observing Genset. The Paris-based company has been rather quiet with its news of late-something of which the company is aware. "We need to demonstrate progress to the market," admits Deborah Smeltzer. "We understand very well that investor patience is wearing thin." There are some crumbs: the pharmacogenomics projects with Abbott (Abbott Park, IL) and Pharmacia \& Upjohn (Bridgewater, NJ); Janssen, the Johnson \& Johnson subsidiary, has apparently extended its collaboration with Genset in schizophrenia through to the end of the year; and Smeltzer says that there will be additional announcements before the end of 1999.

John Hodgson 